\title{
Simultaneous dry-sorption of heavy metals by porous adsorbents during sludge composting
}

\author{
Saim Ozdemir ${ }^{1 \dagger}$, Sinan Mehmet Turp², Nurtac Oz ${ }^{1}$ \\ ${ }^{1}$ Department of Environmental Engineering, Faculty of Engineering, Sakarya University, 54187, Esentepe, Sakarya, Turkey \\ ${ }^{2}$ Department of Environmental Engineering, Faculty of Engineering and Architecture, Bitlis Eren University, 13000, Bitlis, Turkey
}

\begin{abstract}
Heavy metal removal by using porous mineral adsorbents bears a great potential to decontaminate sludge compost, and natural zeolite (NZ), artificial zeolite (AZ), and expanded perlite (EP) seem to be possible candidates for this purpose. A composting experiment was conducted to compare the efficiency of those adsorbents for removal of iron (Fe), manganese $(\mathrm{Mn})$, chromium $(\mathrm{Cr})$, copper $(\mathrm{Cu})$, zinc $(\mathrm{Zn})$, nickel $(\mathrm{Ni})$, and lead $(\mathrm{Pb})$ from sewage sludge compost with no adsorbent amendment. For this purpose, $10 \mathrm{~g}$ of $\mathrm{NZ}$ and $\mathrm{AZ}$ and $5 \mathrm{~g}$ of EP was filled in a small bag made from non-biodegradable synthetic textile and was separately mixed in composting piles. The bags were separated from compost samples at the end of the experiment. AZ and NZ exhibited different reduction potentials depending on the type of heavy metal. AZ significantly reduced $\mathrm{Cr}(43.7 \%)$, Mn (35.8\%), and Fe (29.9\%), while NZ more efficiently reduced Cu (24.5\%), Ni $(22.2 \%), \mathrm{Zn}(22.1 \%)$, and $\mathrm{Pb}(21.2 \%)$. The removal efficiency of EP was smaller than both AZ and NZ. The results of this simultaneous composting and metal removing study suggest that AZ and NZ can efficiently bind metal during composting process.
\end{abstract}

Keywords: Artificial zeolite, Expanded perlite, Heavy metal removal, Natural zeolite, Sludge compost

\section{Introduction}

Water pollution is one of the main environmental concerns causing serious problems in water bodies and damage to living things and human health when discharged without appropriate treatment [1]. Therefore, the removal of various pollutants from urban wastewater has been a core focus over the past decades [2-3]. In this context, municipal wastewater treatment plants increasingly produce large volumes of sewage sludge and their safe disposal is one of the major environmental problems throughout the world [4]. Composting is one of the most applicable practices for handling and final disposal of sewage sludge after appropriate stabilization, due to providing safe disposal and nutrient recycling in agricultural lands [5]. However, heavy metals in sewage sludge are one of the main restrictions on recycling of sludge compost due to possible uptake by plants and accumulation in food chain [6]. This is because during wastewater treatment, more than $50-80 \%$ of heavy metals will be concentrated in treatment residue sludge [7]. The speciation and content of heavy metals directly affect the use of sludge compost for crop production [8].
Among the existing methods for the removal of heavy metals from sludge compost, the adsorption process is one of the most attractive ones, especially when the adsorbent is obtained with a low-cost and occurs naturally in large quantities [9]. Natural adsorbents made from zeolite and perlite contains many characteristics conducive to the retention of heavy metals [10]. The structure zeolites consist of $\mathrm{Si}^{4+}$ and $\mathrm{AL}^{3+}$ that produce a net negative charge that will be balanced by certain exchangeable cations such as cadmium, copper, lead, and zinc [11]. Likewise, expanded perlite has a large external and internal surface area with micro and nanoscale pores and a certain amount of adsorption capacity to heavy metals [10]. Both the high cation exchange capacity (CEC) of natural adsorbents and the amount of oxygen-containing functional groups on their surface are conducive to the retention of heavy metals [12-13]. These characteristics make zeolite and perlite powerful adsorbents for binding heavy metal pollutants.

There have been numerous studies on methods for mitigating heavy metals of sludge compost by using adsorbents; however, most of the research focuses on metal immobilization [12, 14-15]. The reported methods on mitigation of heavy metal contents from
This is an Open Access article distributed under the terms of the Creative Commons Attribution Non-Commercial License (http://creativecommons.org/licenses/by-nc/3.0/) which permits unrestricted non-commercial use, distribution, and reproduction in any medium, provided the original work is properly cited.

Copyright (C) 2020 Korean Society of Environmental Engineers
Received February 24, 2019 Accepted April 11, 2019

${ }^{\dagger}$ Corresponding author

Email: saimo@sakarya.edu.tr

Tel: +90-534-215-53-50

ORCID: 0000-0002-0549-0577 
sewage sludge compost rely on the addition of different natural adsorbents such as zeolite to the composts [16], amendment with lime or biochar [7] for heavy metal passivation, or the use of fungi for the association of metals into humus complex [17]. A number of studies have described the effect of natural adsorbents on the adsorption capacities of heavy metal. The results showed promising application prospects with a significant difference in the adsorption capacity of $\mathrm{Pb}, \mathrm{Cd}, \mathrm{Cu}$, and $\mathrm{Zn}$ between different zeolites and perlites $[13,18]$. The type of natural adsorbent, pore size distribution, functional groups, and elementary composition of natural adsorbents significantly influence the binding capacity of heavy metal from aqueous solutions and metal mobility in composts [10]. For example, the study by Singh and Kalamdhad [19] showed that the zeolite additive mixed to sludge compost at $1 \%$ significantly decreased the leaching risk of heavy metals and bioavailability for plant uptake compared to the non-zeolite mixed compost. Similarly, Nissen et al. [5] incorporated $0.1-1 \%$ synthetic zeolite to sludge compost and reported a significant reduction of labile zinc pool in compost. Villasenor et al. [12] found a 100\% removal of $\mathrm{Ni}, \mathrm{Cr}$, and $\mathrm{Pb}$ when composting sewage sludge with a mixing rate of $10-40 \%$ using different types of zeolite. Likewise, Liu et al. [7] found that incorporation of biochar to sludge compost decreased the bioavailability of $\mathrm{Pb}, \mathrm{Cu}$, and as by more than $50 \%$ and $\mathrm{Cr}$ by more than $30 \%$ after composting. These studies indicate that mixing non-biodegradable natural adsorbents into compost pile during composting could have some significant benefits and is thus considered a major option to mitigate heavy metal fractions from sludge compost.

Although the studies cited above (and other similar studies) have highlighted metal speciation and passivation using natural adsorbents, to the best of the authors' knowledge, little is known about the metal removal potential of porous adsorbents during organic matter decomposition of wastewater sludge composting process. In agricultural and horticultural applications, changing environmental conditions during crop production cycle may alter oxidation, reduction, and $\mathrm{pH}$-dependent reactions that affect bounded forms of metals and can induce bioavailability to plant uptake. Based on the foregoing facts, the present study is a new attempt to fulfil the mentioned gap by focusing upon the effectiveness of porous adsorbents in simultaneous removal of heavy metals from sludge compost under standard composting conditions for $60 \mathrm{~d}$. The tested hypothesis in the present experiment was the ability of porous adsorbents natural zeolite (NZ), artificial zeolite
(AZ), and expanded perlite (EP) to remove heavy metals from the sludge compost when separated from the compost at the end of the composting.

\section{Material and Methods}

\subsection{Composting Feed Stocks}

Dewatered sewage sludge at moisture content of $80 \%$ collected from a local municipal wastewater treatment plant (Karaman, Sakarya Province, Turkey) and hazelnut husk obtained from a local farmer in Sakarya, Turkey were used in this study. NZ, AZ, and EP were purchased from commercially available channels. Chopped hazelnut husk (0-5 mm) was mixed with the sludge as the bulking agent to achieve a moisture content of around $60-65 \%$, an initial bulk density of around $0.5 \mathrm{~kg} \mathrm{~L}^{-1}$, and initial $\mathrm{C} / \mathrm{N}$ ratio 30 . For heavy metal adsorption, $10 \mathrm{~g}$ of NZ and $\mathrm{AZ}$, due to their relatively high specific bulk density of around $0.75 \mathrm{~kg} \mathrm{~L}^{-1}$, and $5 \mathrm{~g}$ of EP, which has a light bulk density of around $0.07 \mathrm{~kg} \mathrm{~L}^{-1}$, was filled in a small non-biodegradable synthetic textile bag separately and homogenously mixed into each separate composting treatment. The selected initial properties of dewatered sludge, hazelnut husk, NZ, AZ, and EP were listed in Table 1.

\subsection{Characterization of Natural Adsorbents}

The surface area, adsorption, desorption, and average pore size of all three adsorbents were measured using the BrunauerEmmett-Teller (BET) method and shown in Table 2. BET surface area analysis was carried out with a Quantachrome Nova Touch LX4 instrument at the Kastamonu University Research Laboratory. The scanning electron microscopic (SEM) and energy dispersive $\mathrm{X}$-ray spectroscopic (EDS) analyses were also performed using the FEI Quanta model FEG 250 instrument (FEI Netherlands) at the Kastamonu University Research Laboratory.

\subsection{Experimental Design}

The present composting experiments were designed in triplicate to evaluate the effect of NZ, AZ, and EP, while without additives amended treatment served as control for comparison purpose. Following the homogenous mixture of dewatered sludge and hazelnut husk, compost samples were homogeneously separated into 4 parts

Table 1. Initial Physicochemical Properties of Composting Materials Sewage Sludge, Hazelnut Husk, Natural Zeolite (NZ), Artificial Zeolite (AZ), and Expanded Perlite (EP)

\begin{tabular}{|c|c|c|c|c|c|}
\hline Parameters & Sewage sludge & Hazelnut husk & NZ & $\mathrm{AZ}$ & EP \\
\hline Organic matter (\%) & $66.23 \pm 1.85$ & $93.06 \pm 1.06$ & ND & ND & ND \\
\hline TOC (\%) & $36.52 \pm 1.27$ & $49.33 \pm 1.21$ & ND & ND & ND \\
\hline Kjeldahl nitrogen (\%) & $3.43 \pm 0.16$ & $0.69 \pm 0.02$ & ND & ND & ND \\
\hline $\mathrm{C}: \mathrm{N}$ ratio & $10.74 \pm 0.34$ & $68.85 \pm 1.88$ & ND & ND & ND \\
\hline Moisture content (\%) & $81.12 \pm 0.88$ & $10.23 \pm 0.02$ & $0.04 \pm 0.01$ & $1.53 \pm 0.12$ & $2.07 \pm 0.10$ \\
\hline $\mathrm{pH}$ & $6.67 \pm 0.15$ & $4.87 \pm 0.12$ & $8.23 \pm 0.24$ & $8.08 \pm 0.15$ & $7.47 \pm 0.04$ \\
\hline $\mathrm{EC}(\mathrm{mS} / \mathrm{cm})$ & $3.61 \pm 0.02$ & $3.02 \pm 0.03$ & ND & ND & ND \\
\hline
\end{tabular}

ND (Not detected), TOC (total organic carbon), EC (Electrical conductivity). Results are the mean of three replicates \pm standard deviation. 


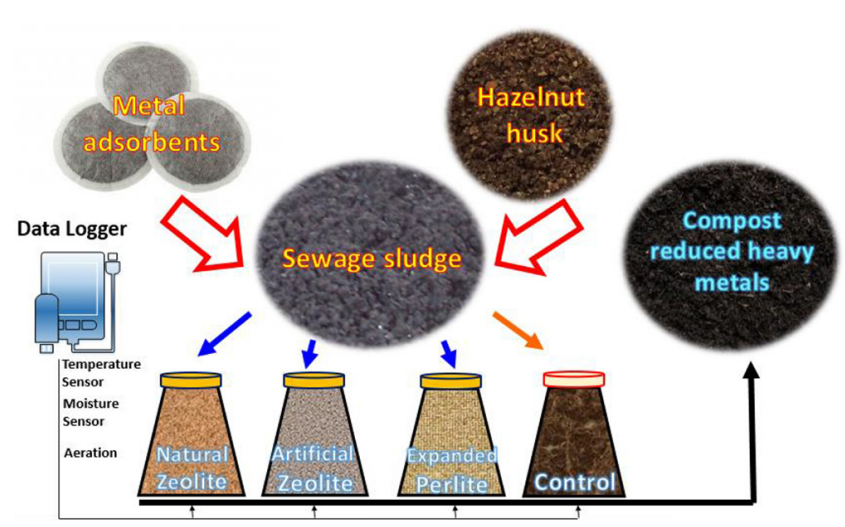

Fig. 1. Schematic view of the composting process, material preparation, and experimental design.

for composting experiments. Equal amounts of subsamples obtained from the initial mixture were loaded into the bench-scale insulated composting containers that were kept at room temperature $\left(25 \pm 2^{\circ} \mathrm{C}\right)$ in the laboratory and composted for $60 \mathrm{~d}$ during the experimental study (Fig. 1). The porous mineral amendment dosages were determined on the basis of previous sewage sludge composting experiments [12-13, 16]. The prepared bags containing NZ, AZ or EP were separately mixed into the tested treatments. No specific aeration system was installed, but the pile was aerated by mixing the content manually every day in order to maintain proper aeration and to increase the contact of the released heavy metals to the adsorbents tested. The heavy metal content in the initial mixture was determined preliminary to composting experiments (Table 3).

Temperature, moisture, and $\mathrm{pH}$, which have more variations on decomposition and metal mobility determining parameters, were monitored during composting. The moisture content of the initial compost pile was adjusted at $60 \%$ through addition of bulking agent and deionized water if necessary. The moisture content was maintained at around $60-65 \%$ throughout the experiment as suggested by previous studies [12, 19]. The temperature and moisture content of the composting mixture was monitored using the temperature and moisture sensor that was inserted into the center of the composting pile and daily temperature changes were noted. For $\mathrm{pH}$ and moisture content determination, the compost mixtures were sampled every $2 \mathrm{~d}$ during the initial active phase and every $5 \mathrm{~d}$ for the rest of the experiment.

\subsection{Analytical Methods and Analysis}

The effects of porous adsorbents on heavy metal reduction in sludge compost were evaluated by obtaining samples (1 $\mathrm{g}$ for each treatment) at the end of the composting experiments. The moisture content of the initial composting materials and compost samples was determined on oven dry weight basis at $105^{\circ} \mathrm{C}$ for about 24 h. The 1:10 aqueous extract (w/v, solid/ultra-pure water on dry weight basis) was used for the analysis of $\mathrm{pH}$ and electrical conductivity (EC) as described by European Standards [4]. The organic matter (OM) content of raw materials and compost samples was measured according to the Walkley and Black method [20]. The organic carbon was analyzed using a total organic carbon (TOC) analyzer (Sievers M5310 C, GE Analytical Instruments, USA). Kjeldahl nitrogen was determined by the Kjeldahl method [4]. For the heavy metal analysis, compost samples obtained at the end of the composting were oven-dried at $78^{\circ} \mathrm{C}$ until reaching a constant weight. Then all the samples $(250 \mathrm{mg})$ were sieved through a 2-mm sieve and were digested in a Microwave Digestion System (Sorisole-Bg Italy) by adding $6 \mathrm{~mL}$ of $\mathrm{HNO}_{3}$ (65\%) and $1 \mathrm{~mL}$ of $\mathrm{H}_{2} \mathrm{O}_{2}$ (30\%) acid mixture. The digested samples were cooled, diluted with ultra-pure water, filtered through Whatman filter paper, and adjusted up to the volume of $50 \mathrm{~mL}$. Then, the contents of $\mathrm{Fe}, \mathrm{Mn}, \mathrm{Zn}, \mathrm{Cu}, \mathrm{Cd}, \mathrm{Cr}, \mathrm{Ni}$, and $\mathrm{Pb}$ were determined with an Inductively Coupled Plasma Optical Emission Spectrometry (ICP-OES, Spectro Arcos, Kleve, Germany).

The heavy metal removal rate was estimated by measuring the heavy metal concentration at finished compost samples using the Eq. (1):

$$
\text { Removal \% = Cc-Ci } / \text { Cc } \times 100
$$

Where, $\mathrm{Cc}$ and $\mathrm{Ci}$ are the concentrations of each heavy metal in the unamended control and in the porous adsorbent amended compost samples $\left(\mathrm{mg} \mathrm{Kg}^{-1}\right)$, respectively.

\subsection{Statistical Analysis}

All the physicochemical analyses in raw materials and compost samples were performed in triplicate. The normality and the variance homogeneity of the data were tested prior to ANOVA. Simple descriptive analysis was applied to determine the average value of the quantitative variables. Meanwhile, multiple comparison tests were also performed to compare the least significance difference (LSD). Statistical analyses were performed using the SPSS software (version 22.0; SPSS Inc., Chicago, IL). $P$ values $<0.05$ were considered significant as the probability levels.

\section{Results and Discussion}

\subsection{Properties of Adsorbents}

The SEM images of natural zeolite (NZ), artificial zeolite (AZ), and expanded perlite (EP) are shown in Fig. 2. The NZ samples showed rather smooth characteristics of scanning electron micrographs compared to both AZ and EP. Such a texture was expected because of the deposition under natural environmental conditions. In this context, such a microstructure causes low internal porosity and low specific surface area, which makes it less suitable to metal binding sites. The high resolution SEM images of AZ indicated a more suitable surface structure for metal sorption. Therefore, it is expected that AZ particles reveal high removal efficiencies for metal pollutants from compost piles. From Fig. 2, it is noted that $\mathrm{EP}$ is rougher and has rather a large pore structure than NZ and $\mathrm{AZ}$, which is most likely due to the expansion of natural perlite during heating process at higher temperatures [10]. Despite the imperfection structure of NZ and EP, the studied samples may involve other chemical properties for removing metals from composts. Similar findings were shown by Villasenor et al. [12] when testing several zeolite samples for metal inactivation in sludge composts. 

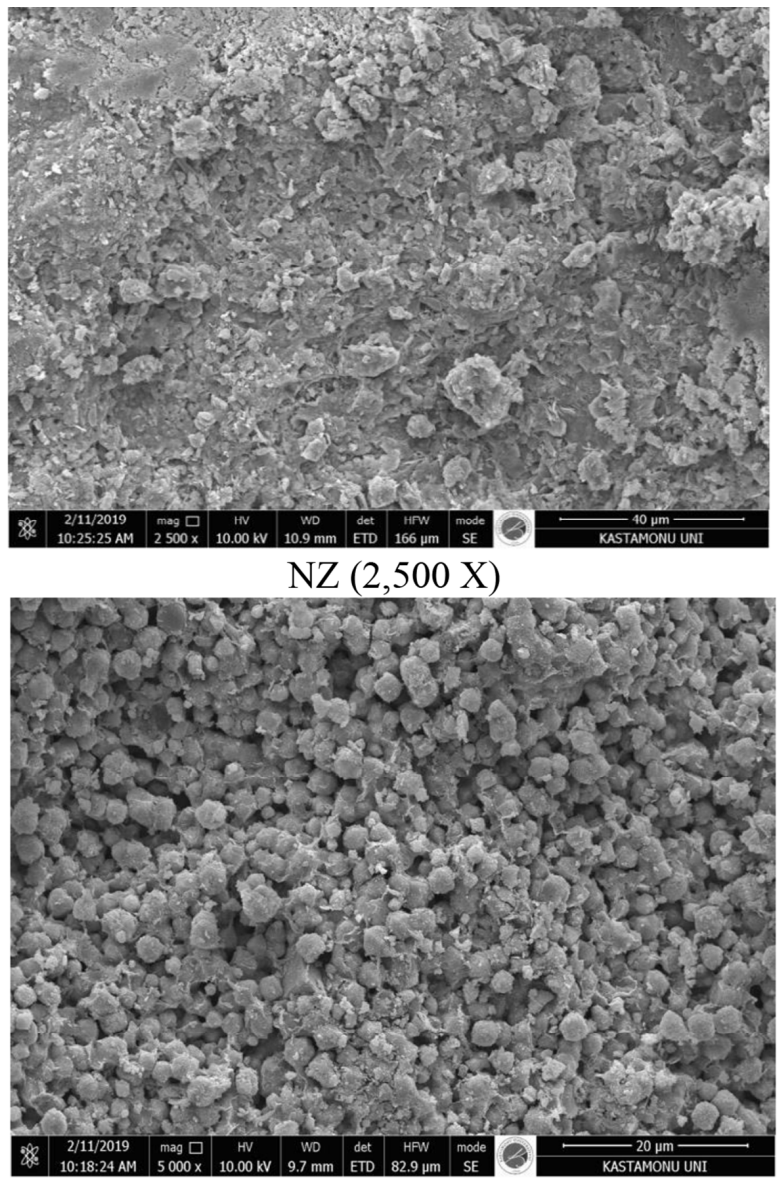

$\mathrm{AZ}(5,000 \mathrm{X})$

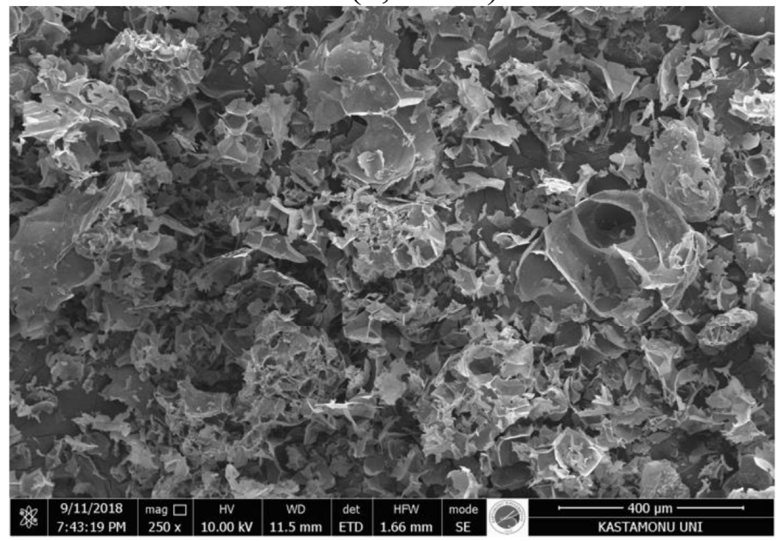

$\mathrm{EP}(250 \mathrm{X})$

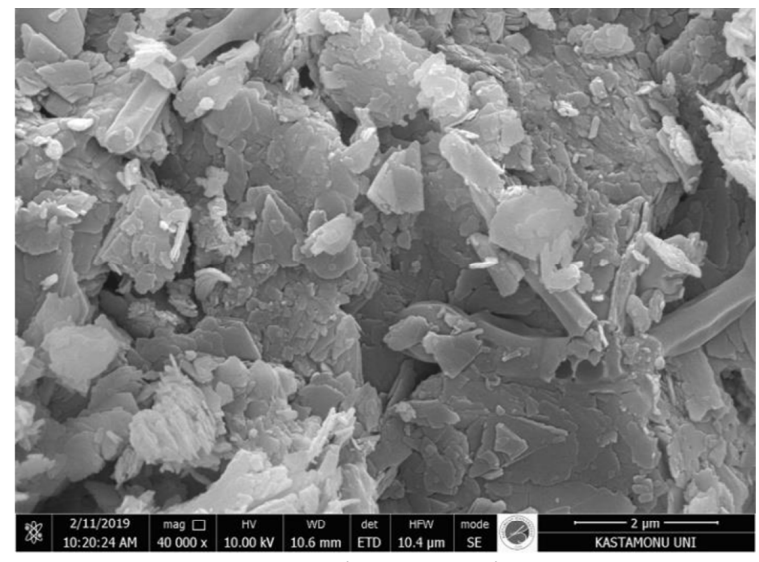

$\mathrm{NZ}(40,000 \mathrm{X})$

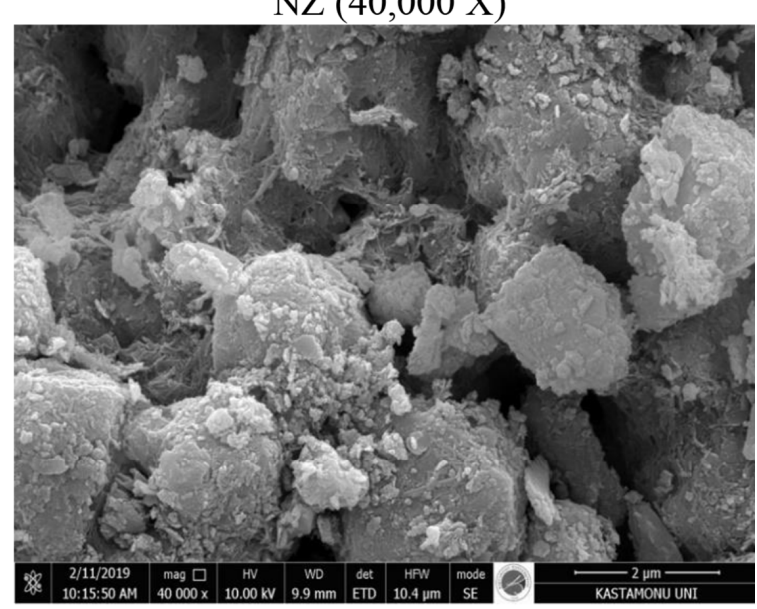

AZ $(40,000 \mathrm{X})$

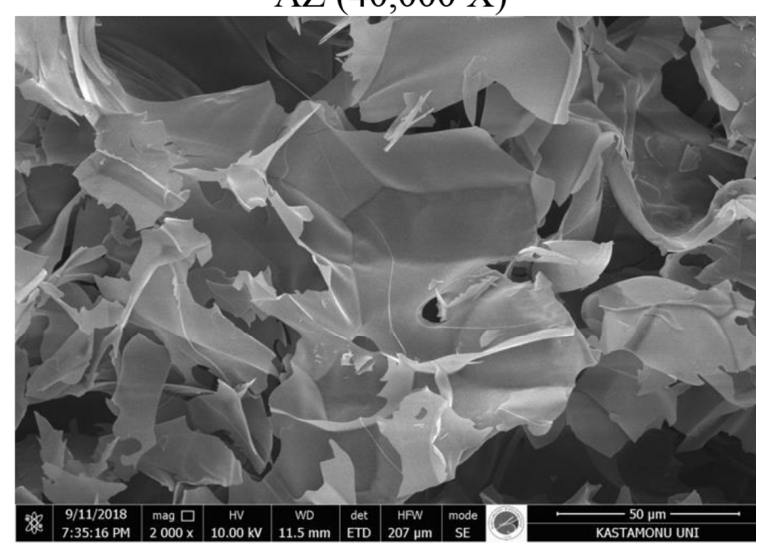

$\mathrm{EP}(2,000 \mathrm{X})$

Fig. 2. SEM images of natural zeolite (NZ), artificial zeolite (AZ), and expanded perlite (EP).

Significant physicochemical characteristics of NZ, AZ, and EP, which will determine metal binding of adsorbents and therefore removal from compost, are presented in Table 2. Sorption and ion-exchange are two important mechanisms for effective removal of heavy metals, therefore BET surface area, pore size distribution, and CEC are the most important determining parameters to describe the suitability of porous adsorbents. In the present study, the BET surface area of the tested adsorbents was 34, 129, and $406 \mathrm{~m}^{2} / \mathrm{g}$ for NZ, AZ, and EP, respectively. The CEC value of AZ (195 meq/100 g) was higher than NZ (127 meq/100 g) and EP (12 meq/100 g), which is close to the reported values for similar porous adsorbents $[10,14]$. The physicochemical properties of porous adsorbents were comparable to the results of previously reported similar research for composting experiments. 
Table 2. Selected Physicochemical Properties of Natural Zeolite (NZ), Artificial Zeolite (AZ), and Expanded Perlite (EP)

\begin{tabular}{lccc}
\hline Parameter & NZ & AZ & EP \\
\hline O (mass \%) & 38.65 & 38.91 & 50.86 \\
Si (mass \%) & 34.02 & 20.39 & 31.61 \\
Al (mass \%) & 7.18 & - & 7.28 \\
Na (mass \%) & - & 12.73 & 3.47 \\
Ca (mass \%) & 3.23 & - & - \\
K (mass \%) & 2.15 & - & 3.71 \\
Surface area (g/m²) & 34 & 129 & 406 \\
Total pore volume (cc/g) & 0.31 & 0.36 & 0.48 \\
Average pore size (nm) & 0.28 & 0.47 & 0.83 \\
CEC (meq 100/g) & 127 & 195 & 12 \\
\hline
\end{tabular}

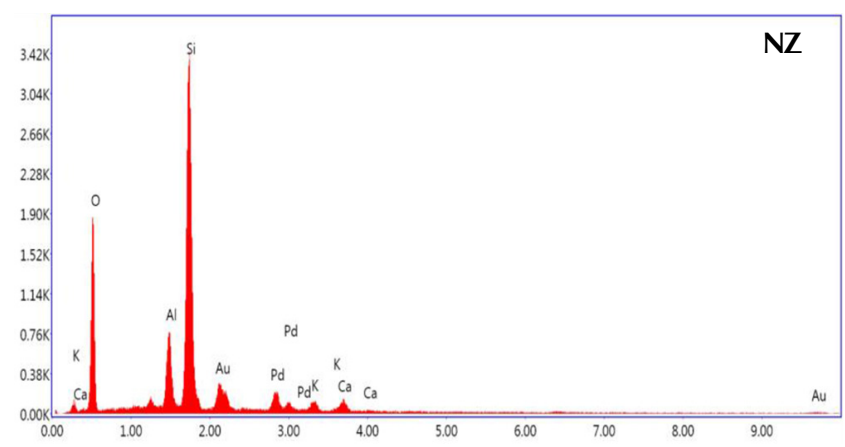

Lsec 28.10 Cnts 0.000 keV Det: Octane Pro Det

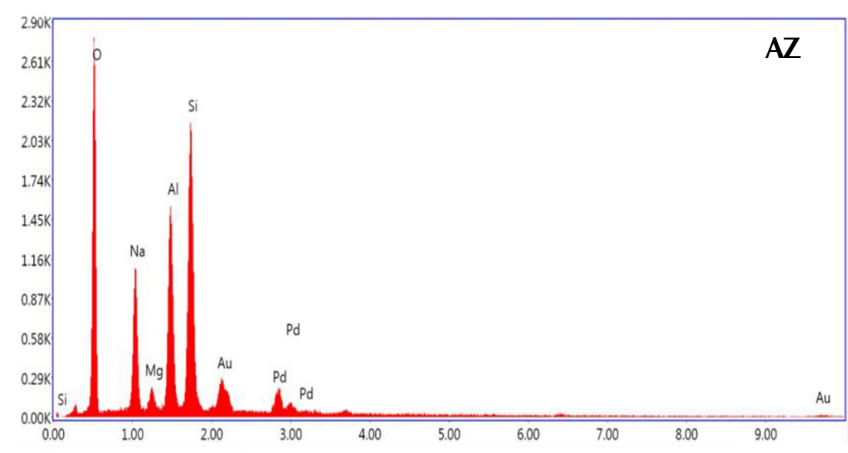

Lsec: 27.90 Cnts 0.000 keV Det: Octane Pro Det

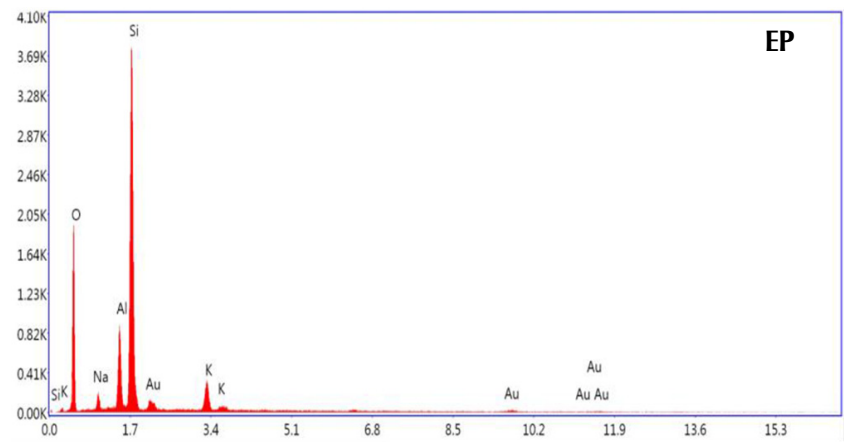

Lsec: 28.00 Cnts 0.000 keV Det: Octane Pro Det

Fig. 3. EDS analysis of natural zeolite (NZ), artificial zeolite (AZ), and expanded perlite (EP).
The energy-dispersive X-ray spectroscopy (EDS) analysis of natural adsorbents NA, AZ, and EP are shown in Fig 3. The high proportion of oxygen content in all three adsorbents indicates the formation of a potential oxide compound such as $\mathrm{SiO}_{2}, \mathrm{Al}_{2} \mathrm{O}_{3}$, $\mathrm{NaO}, \mathrm{CaO}$, and $\mathrm{K}_{2} \mathrm{O}$, which is an indicator of ion exchange and the retention potential of each investigated adsorbent. Therefore, NA, AZ, and EP can be used as metal removal adsorbents and after separation; sludge compost can be safely used for agricultural purposes.

\subsection{Composting Conditions}

Organic matter decomposition and the concurrent release and migration of heavy metals from bounded fractions are determined mainly by temperature rise, $\mathrm{pH}$ in acid ranges, and moisture content in composting pile [7, 12]. The temperature variations in all the treatments were insignificantly on the same line from the initial mesophilic stage ( $3 \mathrm{~d}$ ), the thermophilic stage $(7 \mathrm{~d}$ ), and the following cooling period ( $7 \mathrm{~d}$ ) where the temperature was reduced to ambient levels (Fig. 4). The composting conditions during the thermophilic phase were sufficient for intensive organic matter break-up that enhanced heavy metal release from organic fractions [15].

The $\mathrm{pH}$ variation during composting of each treatment is presented in Fig. 4. The pH clearly decreased during the thermophilic stage of composting and then was stabilized around 6.9-7.2 irrespective of the types of amendment. The formation of organic
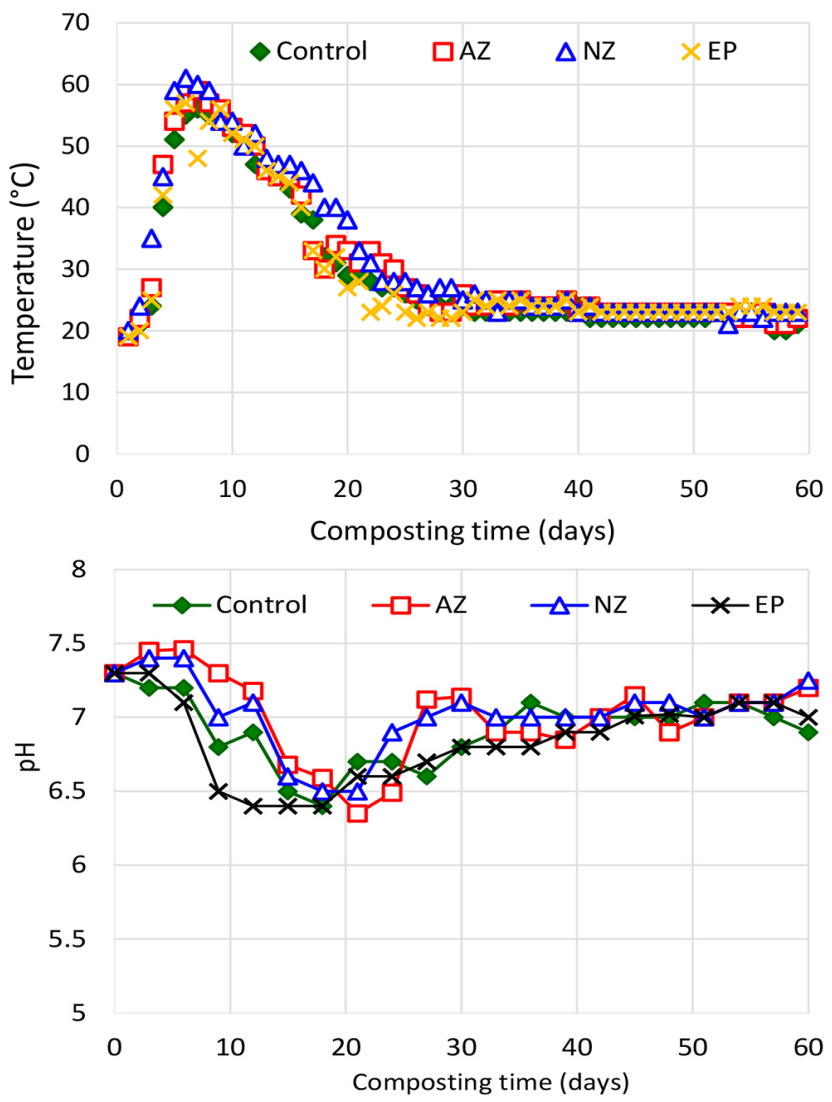

Fig. 4. Temperature and $\mathrm{pH}$ variation during the composting period. 
Table 3. Summary of ANOVA Results and Post Hog Analysis of Total Heavy Metal Concentration (mg/kg dry weight) in Control, NZ, AZ, and EP Treatments after the Composting Process

\begin{tabular}{|c|c|c|c|c|c|c|c|}
\hline \multirow{2}{*}{ Preliminary mixture } & $\mathrm{Fe}$ & Mn & $\mathrm{Cr}$ & $\mathrm{Cu}$ & $\mathrm{Zn}$ & $\mathbf{N i}$ & $\mathbf{P b}$ \\
\hline & 321 & 154 & 18 & 48 & 96 & 13 & 37 \\
\hline $\mathrm{F}$ & 18.44 & 572.82 & 20.92 & 335.56 & 540.40 & 5.61 & 46.33 \\
\hline$p$-value & 0.0006 & 0.0000 & 0.0004 & 0.0000 & 0.0000 & 0.0428 & 0.0000 \\
\hline $\mathrm{NZ}$ & 488 a & $197 \mathrm{c}$ & $42 \mathrm{~b}$ & $74 \mathrm{a}$ & 102 a & $14 \mathrm{a}$ & 52 a \\
\hline AZ & 453 a & 136 a & $27 \mathrm{a}$ & $84 \mathrm{~b}$ & $125 \mathrm{c}$ & $16 \mathrm{ab}$ & $57 \mathrm{~b}$ \\
\hline $\mathrm{EP}$ & $568 \mathrm{~b}$ & $166 \mathrm{~b}$ & $42 \mathrm{~b}$ & $93 \mathrm{c}$ & $122 \mathrm{~b}$ & $15 \mathrm{a}$ & $56 \mathrm{~b}$ \\
\hline Control & $647 \mathrm{c}$ & $212 \mathrm{~d}$ & $48 \mathrm{~b}$ & $98 \mathrm{~d}$ & $131 \mathrm{~d}$ & $18 \mathrm{~b}$ & $66 \mathrm{c}$ \\
\hline LSD & 65.85 & 4.58 & 6.41 & 1.88 & 1.72 & 2.66 & 2.72 \\
\hline
\end{tabular}

$\mathrm{F}=$ likelihood ratio, $P=$ probability. Means followed by the same letters within a column do not differ at $P \leq 0.05$

acids and $\mathrm{CO}_{2}$ during rapid decomposition phase contributes to the decrease of $\mathrm{pH}$ in compost pile [7], which has a positive contribution to the mobility of exchangeable, carbonate and reducible metal fractions [15-17]. Further decomposition of organic acids, nitrification process, and release of base cations stabilize the proceeding $\mathrm{pH}$ variations $[12,14]$. The initial moisture content of all the treatments were adjusted to $60 \%$ and maintained at $60-65 \%$ throughout the experimental period in order to increase heavy metal release and migration within compost pile to increase the possibility of binding to natural adsorbents. Therefore, significant variations in moisture content were not observed in each treatment.

\subsection{Effects of Natural Adsorbents on Compost Metal Concentration}

Table 3 shows the concentration of $\mathrm{Fe}, \mathrm{Mn}, \mathrm{Zn}, \mathrm{Cu}, \mathrm{Cr}, \mathrm{Ni}$, and $\mathrm{Pb}$ after composting in control and porous adsorbent treatments. Based on the ANOVA analysis, greater reductions were observed in $\mathrm{AZ}$ and NZ treatments as compared to EP and control treatments. The order of concentration reduction for different heavy metals was as follows: $\mathrm{Cr}>\mathrm{Mn}>\mathrm{Fe}>\mathrm{Cu}>\mathrm{Ni}=\mathrm{Zn}=\mathrm{Pb}$. The greatest reduction in the concentration of $\mathrm{Cr}, \mathrm{Mn}$, and $\mathrm{Fe}$ in AZ-treated compost can be attributed to the affinity of $A Z$ to the released fractions of those metals and its retention capacity. On the other hand, the adsorption and retention capacity of EP was rather smaller than AZ and NZ, which can be attributed to the low ion exchange site and relatively large pore structure of expanded perlite.

It is demonstrated in earlier studies that the concentration and bioavailability of $\mathrm{Cu}, \mathrm{Cd}, \mathrm{Mn}, \mathrm{Pb}$, and $\mathrm{Zn}$ increased during sewage sludge composting depending on the biodegradation rate due to losses of organic matter mass [16, 19]. Therefore, certain passivation methodologies have been applied to remove metals released from organic matter $[12,16]$. Previous studies reported that the most important adsorption phenomena in natural adsorbents such as zeolite and perlite particles are cation exchange, adsorption on the surfaces, and chemisorption of cations on the edge surfaces [10]. The zeolite layer edges are with negatively charged Si and $\mathrm{Al}$ oxides and have a strong affinity to complexation with metal cations from the solution [11]. The noted decrease of heavy metal concentration in the final compost samples in the present study (Table 3) suggests that composting moisture and $\mathrm{pH}$ profile pro- vided sufficient metal mobility and migration for binding exchangeable and reducible metal fractions onto the tested natural adsorbents [12]. Zorpas et al. [16] reported the following order of adsorption to zeolite-amended sewage sludge compost; $\mathrm{Ni}>\mathrm{Pb}>\mathrm{Zn}>$ $\mathrm{Fe}>\mathrm{Cr}>\mathrm{Cu}$, due to the competition between the ions for the negatively charged surface. In the case of $\mathrm{Si}, \mathrm{Al}$ oxides and their interface are the main mechanism for adsorption of metal ions. The different structure and binding sites might be the reason for adsorbing more $\mathrm{Cr}, \mathrm{Mn}$, and $\mathrm{Cu}$ for $\mathrm{AZ}$ as distinct from $\mathrm{NZ}$ and EP. Zorpas et al. [16] demonstrated that more than $30-50 \%$ of heavy metals in sludge compost was released into mobile form and adsorbed onto zeolite in their composting experiment. The rest is retained mainly in organic matter and crystal structure of inorganic complex [15]. Accordingly, all the investigated heavy metals are reduced in compost samples, and the remaining fractions might be in organic matter and residual forms as suggested by previous studies [12, 19].

\subsection{Heavy Metal Removal Rate}

Fig. 5 illustrates the removal percentages of $\mathrm{Fe}, \mathrm{Mn}, \mathrm{Zn}, \mathrm{Cu}, \mathrm{Cr}$, $\mathrm{Ni}$, and $\mathrm{Pb}$ from sludge compost after the composting process. All the investigated heavy metals exhibited reduced concentrations at the end of the composting process compared to the unamended control treatment (Fig. 5). Higher removal rates for $\mathrm{Cr}, \mathrm{Mn}$, and Fe were observed of about $43.75 \%$, 35.85\%, and $29.98 \%$, respectively, in AZ. Higher removal rates for Cu (24.44\%), Ni (24.22\%), Zn (22.14\%), and $\mathrm{Pb}$ (21.21\%) were observed in NZ treatments. The heavy metal reduction capacity of EP was smaller than both zeolite types for all the investigated heavy metals (Fig. 5).

Heavy metals are mainly present in organic forms in sewage sludge compost [16] and are released by the decomposition of organic materials during composting process [7]. It was observed that significant percentages of the released $\mathrm{Cr}, \mathrm{Mn}$, and Fe fractions were adsorbed by AZ. Similarly, but to a lesser extent, $\mathrm{Cu}, \mathrm{Ni}$, $\mathrm{Zn}$, and $\mathrm{Pb}$ were adsorbed by NA during composting. The adsorption behavior of AZ, NZ, and EP may be explained by different structural frameworks of adsorbents such as effective surface area, pore size, and CEC, and the nature of metals such as hydrated size, ionic potential, and hydrolysis constant [21]. The suitable surface structure together with more exchangeable sites of $\mathrm{AZ}$ 


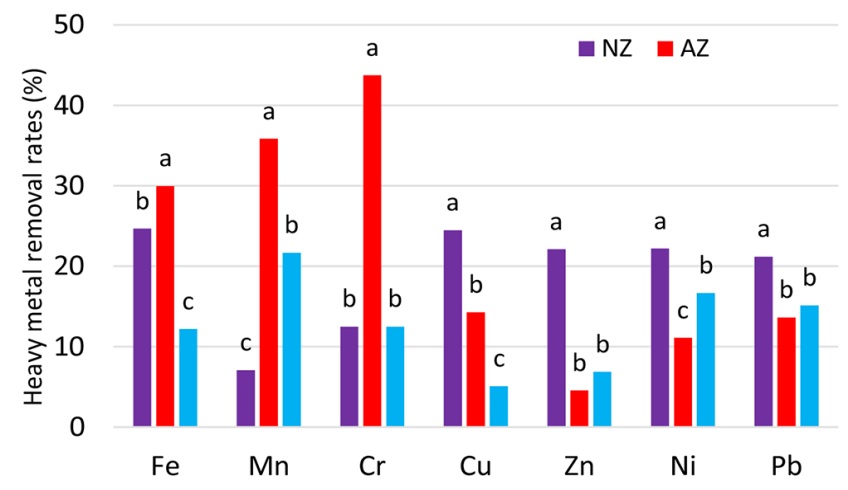

Fig. 5. Removal percentages (\%) of heavy metal from sludge compost by natural zeolite (NZ), artificial zeolite (AZ), and expanded perlite (EP). Values with the same letter within an individual metal are not significantly different at $P \leq 0.05$.

could be the reason for significant enhancement in the removal efficiency of heavy metals compared to NZ and EP. The variations in metal passivation of natural adsorbents such as different types of zeolite were also observed by Villasenor et al. [12], and metal selectivity was explained by operating conditions and the mobility of exchangeable and carbonates fractions present in compost mixture. During composting sludge amended with zeolite, Singh and Kalamdhad [15] found that the bioavailability of $\mathrm{Cu}, \mathrm{Ni}$, $\mathrm{Pb}$, and $\mathrm{Cr}$ decreased. Similar findings were also observed by Liu et al. [7] who composted sewage sludge with zeolite forms. These observations also confirmed the release and mobility characteristics of heavy metals from organic fraction into exchangeable pool and the binding selectivity of the tested adsorbents in the present study. The release and mobility of $\mathrm{Cr}, \mathrm{Mn}$, and Fe were the highest while the mobility of $\mathrm{Pb}, \mathrm{Ni}$, and $\mathrm{Zn}$ was the lowest among the studied metals. Therefore, AZ had the highest affinity and removal capacity for $\mathrm{Cr}, \mathrm{Mn}$, and $\mathrm{Fe}$ than $\mathrm{Ni}, \mathrm{Pb}, \mathrm{Zn}$, and $\mathrm{Cu}$. AZ and NZ also confirmed their ability to adsorb in inner-sphere surface complex, retaining metals less mobile in the compost [15-16].

\section{Conclusions}

Decomposition of sewage sludge organic matter during composting releases a certain amount of heavy metals into ion exchange pool. In the current study, inorganic adsorbent materials AZ, NZ, and EP were investigated to remove the released heavy metals from sludge composting. Non-biodegradable adsorbents had a significant effect on the removal of heavy metals. The removal percentages of $\mathrm{Cr}$ (43.75\%), Mn (35.85\%), and Fe (29.98\%) were higher in AZ, and those of $\mathrm{Cu}$ (25.49\%), Ni (22.22\%), Zn (22.14\%) and $\mathrm{Pb}(21.21 \%)$ were higher in $\mathrm{AZ}$. The retention and removal capacity of EP was relatively small for all the investigated heavy metals. The results of the study have demonstrated the feasibility of composting sewage sludge with artificial and natural zeolite in order to remove the exchangeable fractions of heavy metals from compost and to produce safe compost for agricultural applications.

\section{References}

1. Cakmak B, Apaydin H. Advances in the management of the wastewater in Turkey, natural treatment or constructed wetlands. Spanish J. Agric. Res. 2010;1:188-201.

2. Salihoglu NK. Assessment of urban source metal levels in influent, effluent, and sludge of two municipal biological nutrient removal wastewater treatment plants of Bursa, an industrial city in Turkey. CLEAN Soil, Air, Water 2013;41:153-165.

3. Seiple TE, Coleman AM, Skaggs RL. Municipal wastewater sludge as a sustainable bioresource in the United States. J. Environ. Manage. 2017;197:673-680.

4. Ozdemir S, Dede OH, Yaqub M. Assessment of long-term nutrient effective waste-derived growth media for ornamental nurseries. Waste Biomass Valor. 2017;8:2663-2671.

5. Nissen LR, Lepp NW, Edwards R. Synthetic zeolites as amendments for sewage sludge-based compost. Chemosphere 2000;41:265-269.

6. Dede G, Ozdemir S, Dede OH, Altundağ H, Dündar MŞ Kızloğlu FT. Effects of biosolid application on soil properties and kiwi fruit nutrient composition on high-pH soil. Int. J. Environ. Sci. Technol. 2017;14:1451-1458.

7. Liu W, Huo R, Xu J, et al. Effects of biochar on nitrogen transformation and heavy metals in sludge composting. Bioresour. Technol. 2017;235:43-49.

8. Dede G, Ozdemir S. Effects of elemental sulphur on heavy metal uptake by plants growing on municipal sewage sludge. J Environ. Manage. 2016;166:103-108.

9. Varank G, Demir A, Bilgili MS, et al. Equilibrium and kinetic studies on the removal of heavy metal ions with natural low-cost adsorbents. Environ. Prot. Eng. 2014;40:43-61.

10. Turp SM. $\mathrm{Mn}^{2+}$ and $\mathrm{Cu}^{2+}$ adsorption with a natural adsorbent: Expanded perlite. Appl. Ecol. Environ. Res. 2018;16:5047-5057.

11. Turp SM. Prediction of adsorption efficiencies of Ni (II) in aqueous solutions with perlite via artificial neural networks. Arch. Environ. Prot. 2017;43:26-32.

12. Villasenor J, Rodriguez L, Fernandez FJ. Composting domestic sewage sludge with natural zeolites in a rotary drum reactor. Bioresour. Technol. 2011;102:1447-1454.

13. Awasthi MK, Wang M, Pandey A, et al. Heterogeneity of zeolite combined with biochar properties as a function of sewage sludge composting and production of nutrient-rich compost. Waste Manage. 2017;68:760-773.

14. Turan NG, Ergun ON. Improving the quality of municipal solid waste compost by using expanded perlite and natural zeolite. CLEAN Soil, Air, Water 2008;36:330-334.

15. Singh J, Kalamdhad AS. Influences of natural zeolite on speciation of heavy metals during rotary drum composting of green waste. Chem. Speciation Bioavailability 2014;26:65-75.

16. Zorpas AA, Inglezakis VJ, Loizidou M. Heavy metals fractionation before, during and after composting of sewage sludge with natural zeolite. Waste Manage. 2008;23:2054-2060.

17. Zhang C, Xu Y, Zhao M, Rong H, Zhang K. Influence of inoculating white-rot fungi on organic matter transformations and mobility of heavy metals in sewage sludge based composting. J. Hazard. Mater. 2018;344:163-168.

18. Tarlan-Yel E, Önen V. Performance of natural zeolite and sepio- 
lite in the removal of free cyanide and copper-complexed cyanide $\left(\left[\mathrm{Cu}(\mathrm{CN})_{3}\right] 2^{-}\right)$. Clays Clay Miner. 2010;58:110-119.

19. Singh J, Kalamdhad AS. Effects of lime on bioavailability and leachability of heavy metals during agitated pile composting of water hyacinth. Bioresour. Technol. 2013;138:148-155.

20. Ryan J, Estefan G, Rashid A. Soil and plant analysis laboratory manual. 2nd ed. International Center for Agricultural Research in the Dry Areas (ICARDA) and the National Agricultural Research Center (NARC); Aleppo: ICARDA; 2001. p. 5-146. 21. Wang C, Li JS, Sun X, Wang L, Sun XY. Evaluation of zeolites synthesized from fly ash as potential adsorbents for wastewater containing heavy metals. J. Environ. Sci. 2009;21:127-136. 